\title{
Reason and Imagination in Charles S. Peirce
}

\section{Sara Barrena}

\section{OpenEdition}

\section{Journals}

Electronic version

URL: http://journals.openedition.org/ejpap/575

DOI: 10.4000/ejpap.575

ISSN: 2036-4091

\section{Publisher}

Associazione Pragma

\section{Electronic reference}

Sara Barrena, «Reason and Imagination in Charles S. Peirce », European Journal of Pragmatism and American Philosophy [Online], V-1 | 2013, Online since 16 July 2013, connection on 19 April 2019. URL: http://journals.openedition.org/ejpap/575; DOI : 10.4000/ejpap.575

This text was automatically generated on 19 April 2019

\section{(c) (i) $\odot$}

Author retains copyright and grants the European Journal of Pragmatism and American Philosophy right of first publication with the work simultaneously licensed under a Creative Commons AttributionNonCommercial-NoDerivatives 4.0 International License. 


\title{
Reason and Imagination in Charles S. Peirce
}

\author{
Sara Barrena
}

Charles S. Peirce was always interested in investigating how reason functions and in explaining how new ideas arise. As a result of his research in this area, linked to the development of pragmatism - which emphasizes the clarification of concepts by means of their "reasonable" consequences - he arrived at a conception of reason as being profoundly creative, and which directs other capacities and interacts with them. Peirce writes: "what he adores, if he is a good pragmaticist, is power; not the sham power of brute force, which, even in its own specialty of spoiling things, secures such slight results; but the creative power of reasonableness, which subdues all other powers, and rules over them with its sceptre, knowledge, and its globe, love" (CP 5.520, c.1905).

In this article I aim to explore Peircean creativity more deeply, focusing on one of its essential, thought perhaps less studied, elements: the imagination. This faculty should be taken more into account, given that Peirce affirms that the whole business of ratiocination, and all that makes us intellectual beings, is performed in imagination (CP $6.286,1893)$. Hence it is necessary to study a connection - that between reason and imagination - in which the most important aspects of the Peircean conception of reasonableness are rooted. As Andacht has written: "it is not exaggerated to talk about a 'revolution'... when one evaluates historically the theoretical integration of imagination and rationality, of esthetics and action, such as it was done by Peirce..." (Andacht 1996: 1266). What does Peirce understand by imagination? How is its connection with reason produced? In addition to the obvious role of imagination in the process of abduction, i.e. in the origin of possible explanatory hypotheses, pragmatist imagination also performs other functions. It is fundamental in mathematical thought, in philosophical reasoning, and in all aspects of knowledge, since for Peirce understanding the world means interpreting it, and we cannot interpret without imagination.

This article, written based on Peirce's illuminating texts about imagination, is divided into five parts. In the first part, I will explain the necessity of the imagination for 
understanding the world. Next, I will focus on the principal characteristics that Peirce attributes to the imagination, followed by an analysis of the role that this faculty develops within Peircean pragmatism. The fourth part will illustrate, by means of examples, how Peirce deals with imagination in different areas of his thought. Finally, I will consider the conjunction of reason and imagination itself, in order to disentangle the different mechanisms by which this conjunction comes into play: habits, surprise, doubt, belief and expectations.

\section{The Necessity of Interpretation}

Usually Peirce is classified as a realist philosopher, or at least one who was on a trajectory towards realism. Nevertheless, it is important to note that Peirce's realism is sui generis. For him, things are there, outside of ourselves. What is real is precisely that which our thought cannot modify, and hence is what it is independently of what we may think or imagine about it. Nevertheless, for Peirce it was insufficient merely to explain a reality which is, in some manner, transparent: rather, one must interpret it. His notion of semiotics, in which everything is a sign and knowledge is mediated by signs - or more correctly, is itself constituted as a sign - involves the necessity of interpreting the world. Reality is that which is independent of what we think, but which nevertheless generates interpretants that reveal it, in the infinite process of signification. As Mariluz Restrepo points out:

Peirce uses splendid metaphors in order to express what we do with the phenomenon under study: 'absorb it,' 'sleep over it,' 'assimilate it,' 'dream of it, 'set it down upon paper,' 'digest it, ' 'give it an order,' 'deliver it in a form,' (MS 857, 4-5, n. d.), that is, interiorize it in such a way that we penetrate it while at the same time we are penetrated by it. We also register it, ponder it and organize it, seeking to discover that which explains it and thereby be able to comprehend it. (Restrepo 2011)

Our manner of knowing is precisely that of performing a re-creative reading of reality, which we could not accomplish without the imagination. Observation alone cannot be constitutive of investigation or knowledge. There must be a meticulous process of thought, by means of which the ideas given by observation produce others in the mind ( $\mathrm{W}$ 3.41-42). This investigation, by means of which we attain a grasping of the world, is not, for Peirce, "a merely rational process, but rather is 'reasonable,' and includes senses, imagination and memory; desires, projects and hopes; ideas, concepts and arguments" (Restrepo 2011).

Imagination is required at the moment of grasping the world because, for Peirce, knowledge is interpretation; it involves combining observation with reflection until the mind finally renders up to us the facts in a given fashion which explains them. This interpretation must be, as I will show, both imaginative as well as rigorous. Reason and imagination go hand in hand.

7 This equilibrium between a reality that is what it is while simultaneously being open to interpretation, between the application of reason and the imagining of an explanation, is present throughout the entirety of Peirce's thought. We cannot know without imagining. This intimate union of reason and imagination, which is perhaps most evident in science or art, occurs in each of our reflections - or interpretations - concerning reality, whatever their order may be, and makes pragmatism a creative philosophy. 


\section{Peirce's Concept of the Imagination} intellectual trajectory is marked by many discoveries in different fields which he would not have achieved without a powerful imagination: from the fruitful pragmatic maxim to his omnipresent triadic system of categories. Peirce embodies creative thought, which oscillates between reason and imagination. He has much to say about the latter and about the plasticity which it confers on the human being. Peirce deals with the question of imagination more than we sometimes think. For instance, the references to imagination in Collected Papers are abundant, and many of these texts shed light upon the role of the most creative faculty of the human being. Imagination appears in these texts as something distinct from mere fantasizing. Peirce makes a distinction between imagination and fantasy, which Howard Callaway has examined in the light of certain antecedents in Coleridge and Emerson. We can cite, for example, a suggestive text by Emerson:

Imagination is central; fancy superficial. Fancy relates to surface, in which a great part of life lies. The lover is rightly said to fancy the hair, eyes, complexion of the maid. Fancy is a willful imagination, a spontaneous act; fancy, a play as with dolls and puppets which we chose to call men and women; imagination, a perception and affirming of a real relation between a thought and some material fact. Fancy amuses; imagination expands and exalts us. Imagination uses an organic classification. Fancy joins by accidental resemblance, surprises and amuses the idle, but is silent in the presence of great passion and action. Fancy aggregates; imagination animates. Fancy is related to color; imagination to form. Fancy paints; imagination sculptures. (Emerson 1875)

Imagination has the capacity of penetrating, expanding, animating. For Peirce it consists in "the power of distinctly picturing to ourselves intricate configurations" (MS 252, n.d.). Nevertheless, pragmatist imagination, as Thomas Alexander has written, is not merely the psychological property of having images of absent or non-existent objects, nor it is only a power for unlimited creativity beyond any rational comprehension, as was the Romantic imagination; rather, it offers a radically different perspective:

Imagination is neither merely an extension of the passive capacity of sensation, subsumable under pre-established rational categorial structures, nor is it a purely intuitive source of novelty. It is a mode of action and as such seeks to organize experience so that it anticipates the world in a manner that is meaningful and satisfying. In more human terms, it is an essential and necessary element in our perpetual project of making sense of life. (Alexander 1990: 341)

11 Imagination, for Peirce, is not a mere producer of images nor a wide-awake dreaming, a merely lazy mind. It is neither a fantasy nor a perception, although the (uncontrollable) percipuum can be converted, Peirce writes, into a controllable imagination by a brief process of education (CP 7.646, 1903). Imagination does not function in an uncontrolled fashion; rather, it can be educated and helps us to grow. One must not confuse the great potential of the imagination with mere fantasy, since for Peirce the castles that we build in the air must be copied, with effort, on the ground: "every man who does accomplish great things is given to building elaborate castles in the air and then painfully copying them on solid ground... Mere imagination would indeed be mere trifling; only no imagination is mere" (CP6.286, 1893). Imagination should stimulate and orient our action. 

dreams of explanations and laws, the artistic, and the mere dreaming of opportunities for gain (CP 1.48, c.1896). Of course, imagination is a fundamental tool in art, but science also requires as a prelude a pretty wild play of the imagination (CP 1.48), and this holds for knowledge of any given order. It is indispensable for knowing the truth. This is so much the case, Peirce affirms, that man's mind has a natural adaptation to imagining correct theories of some kinds (CP 5.591, 1903). The scientist, honest, disinterested, indeed any kind of researcher, is precisely that person who places his or her imagination at the service of the truth. He looks for reasonable hypotheses or conjectures which have a certain basis, as opposed to purely fantastic ones. Scientists seek explanations which take into account that which has come before, accumulated knowledge, living science. They do not seek fantastic conjectures, but reasonable ones, hypotheses which take into account the continuity of research in order to distinguish that which is both imaginative and useful from merely fantasy. There is an imagination which is genuinely creative and appropriately disciplined, which arises from the tension between a systematic and detailed consideration of past attainments in a field and its outstanding problems and anomalies (Callaway 2007). distinguished from the actual world by any description (CP 3.363, 1885). The imagination permits us to come to know something more than what is immediately present (CP $1.38,1890)$, there is in it such an operation by which thought springs up (CP 1.538, 1903), allows that phenomena connect themselves together in a rational way (CP 1.46, c.1896), and expands our environment while permitting us to discover unexpected solutions.

The imagination permits us to enjoy freedom, because for Peirce the products of the imagination are not necessarily determined in all their aspects, as Berkeley, for instance, sustained. The imaginary does not have existence in the sense understood by Peirce; it does not react to anything, it suffers no resistances and hence provides us with greater freedom. There is a free play of the imagination which is essential to art and science, and which permits the continuity of ideas, since new ideas must have always been taken in imagination before the old ones are allowed to drop (CP 7.429, 1893). Peirce terms this imaginative play musement, and it is what makes abduction possible, that is, a particular state of mind which passes freely from one thing to another. Musement is a mental state characterized by free speculation, without rules or purpose or limits of any kind. The mind plays with ideas and can sustain a dialogue with what it perceives, a dialogue not only of words but also of images, in which the imagination plays an essential part.

Imagination has nothing to do with issues of fact or with states of things which might at some point come about; rather it deals with non-existent states of things, and with the manner in which unoriginal parts unite to give rise to something original, since originality is not an attribute of the matter of life, but is an affair of form, of the way in which parts none of which possess it are joined together (CP 4.611, 1908). Since it has nothing to do with facts, the imagination can give rise to necessary knowledge, as occurs in mathematics. How can it be that the freest faculty of all, the least subject to rules, which permits us to fly and build castles in the air give rise to necessary knowledge? For Peirce it is possible because necessary knowledge does not follow a path which cannot be deviated from: "Much unexpected truth may often be brought to light by the repeated reintroduction of a premise already employed" (CP 4.611). It is frequently the case that

European Journal of Pragmatism and American Philosophy, V-1 | 2013 
the necessary reasoner encounters distinct lines of reasoning which open before him or her. It is false that in necessary reasoning little space is left for the exercise of invention.

In sum, there is no other quality which is so indispensable for knowledge as the imagination. It does not consist in mere fantasies, but rather has an essential scientific function, where we understand science to encompass all true knowledge and all artistic expression. Following Emerson, one can say that for Peirce the imagination is constructive, cognitively oriented, and examines relations, forms and possibilities. Without its creative work the inquirer would have no world to explore, no determinate hypothetical state of affairs to investigate with the rigor of reasoning (Campos 2009: 137). Imagination is linked with action, and with the desire to know. In what follows I will show how pragmatism makes use of this tool.

\section{The Role of Imagination in Pragmatism}

17 "All scientific men are engaged upon nothing else than the endeavor to discover," writes Peirce (MS 1334), and one can say that an emphasis on discovery is an emphasis on imagination. While the role that, for Peirce, experience plays in knowledge has been strongly emphasized, the role of the imagination has not been studied to the same degree. This is despite the fact that Peirce himself affirms that there are two fundamental kinds of reasoning: the imaginative and the experiential, that is, reasoning by means of diagrams or reasoning by means of experiments (CP 4.74, 1893). Experience and imagination are two complementary wellsprings, which do not always go hand in hand. At times, the imagination works without directly depending on experience, as in the case of certain mathematical conceptions which do not derive from physical experience (CP $4.238,1902)$. For example, conceiving the idea of imaginary quantity and imagining nonEuclidian measurement, both take place in the thoroughly theoretical context of a hypothetical state of things, and mathematicians exercise "immense genius" in creating them in order to solve pure mathematical problems (CP 4.238, 1902). Experience makes possible the creative work of the mathematical imagination, but it is not a necessary condition (Campos 2009: 138).

Pragmatism, which Peirce did not consider to be a philosophical doctrine, but rather the expression of the genuine scientific method - beginning with experience and returning to it in order to confirm hypotheses and concepts on the basis of their effects - involves a defense of imagination, which must be put into play in order to explore the possible consequences of the concepts and the reasonable actions to which it may give rise. The method of pragmatism prescribes to trace out in the imagination the conceivable practical consequences of the affirmation or denial of the concept (CP 8.191, c.1904), which in turn permits the clarification and development of the concept, such that its meaning may transcend mere effects in the here and now, thereby attaining the realm of the possible: "[the method] allows any flight of imagination, provided this imagination ultimately alights upon a possible practical effect [...] it makes conception reach far beyond the practical" (CP 5.196, 1903). In this way, the actual is reinterpreted and reconstructed in the light of what is possible, and human reason is conceived of in a way that is radically different from the traditional vision of rationality, which leaves imagination out. The imagination is no longer seen as a spontaneous and undisciplined faculty, but rather as something which actively intervenes in the clarification and development of our ideas, integrating with rationality and action. In this way the role of 
the non-propositional in our experience, i.e. the aesthetic dimension of rationality, is taken into account (Alexander 1990: 325-6).

In the process of investigation defended by pragmatism, the imagination is necessary at every step. It is necessary, of course, for arriving at hypotheses through abduction. Abductive reasoning presupposes an imaginative effort of understanding, beginning with an "aesthetic-hypothetic" response to the world (Alexander 1990: 329). Abduction involves a creative use of the imagination: the scientist asks his or her imagination about how things might be, imagines possible explanations and makes suppositions which, according to Peirce, constitute an increase of information (CP 2.430, 1893).

In order that science may advance it is necessary to imagine distinct things, and Peirce himself, as a scientist and practical thinker, practices what he preaches. His work is filled with imaginative conjectures and suppositions which help him in his reasoning: for example, let us imagine, states Peirce, that that separate corpuscles related to atoms are endowed with free will (CP 1.261, c.1902); imagine that at a certain moment velocity was suddenly imparted to every atom and corpuscle of the universe (CP 1.274, c.1902); we may imagine the atom of argon to be really formed of four triads (CP 4.309, c.1902), or imagine some molecules as something like little solar systems, only vastly more complex (CP $6.283,1893)$, however, we can hardly imagine that the number of atoms in protoplasm is much less than a thousand (CP 1.393, c.1890). In some texts, Peirce imagines that he is seeking to explain a given doctrine to someone that doesn't know it, or he speaks with imaginary interlocutors. Numerous texts begin with "let us imagine" or "let us suppose." He uses imaginative metaphors, such as his comparison of consciousness to a bottomless lake in which ideas are suspended at different depths, with a constant rain of perceptions that falls upon it (CP 7.553, n.d.). In order to evaluate certain arguments, Peirce also uses his imagination; for instance, in order to evaluate the Neglected Argument for the Reality of God he imagi- nes how it would be considered by three types of people: the first of small instruction, the second inflated with current notions of logic, and the third a trained man of science (CP 6.478, 1908).

Within pragmatism the imagination is not only necessary for coming up with hypotheses, but also for testing them. Indeed, in the texts of Peirce we find that the imagination constitutes the first test for hypotheses. One must discern, prior to taking any other step, whether something is imaginable or not. For Peirce, it is possible that we might have an idea, while nonetheless concluding that it cannot be imagined. In turn, whatever cannot be imagined must be rejected. Thus, if a scientist is confronted with a hypothesis of any order, it is necessary that he or she ask "does the hypothesis hold up in the world of the imagination?" and "does it hold up in that creative world which is not merely a fantasy, but possesses its own proper logic?" In addition, these first imaginary experiments cost very little, as Peirce notes.

Furthermore, Peirce considers the criterion of inconceivability as fundamental for knowing whether a proposition is necessarily true, i.e. to test whether its negation is inconceivable. A proposition will necessarily be true if it is impossible to imagine a state of things in which it would be false, a state not merely unrealizable in imagination today but unrealizable after indefinite training and education (CP 2.29, c.1902).

The imagination, nonetheless, not only intervenes in these first moments of testing a hypothesis, but also during the entire process. Methodeutic logic impels us to pursue, to choose between possible explanations, that which is most simple, where 'simple' means 
for Peirce "more facile of human imagination" (CP 4.644, 1908), and with the least possible number of arbitrary conventions.

We can thus conclude that imagination not only has to do with abduction - the inventive phase of science - but also with the second and third forms of reasoning, i.e. with deduction (the explanatory phase) and with induction (the verification phase). Imagination, moreover, plays an important role in the handling of hypotheses, in the development of their possible consequences and in their verification. The warrant of deduction is that the facts presented in the premisses could not under any imaginable circumstances be true without involving the truth of the conclusion. That is, we cannot imagine a state of things in which the premises are true without the conclusion also being true (CP 2.778, 1901). In the case of induction, there are things that can be proved inductively by imagining and analyzing instances of the surdest description (CP 5.448, 1905).

Peirce thus defends the role of imagination as part of the correct method of research, and we can verify, as I will show in what follows, that his defense and usage of the imagination appear in numerous different parts of his system of thought. I will briefly provide some examples of the role which Peirce assigns to this faculty.

\section{Some Applications of the Imagination Within Peirce's System}

\section{Imagination and Mathematics}

One of Peirce's most vehement defenses of the imagination is that which he makes within the realm of mathematics. The imagination is central for a deductive science such as mathematics, since 'deductive' does not mean for Peirce that a science is mechanical or lacking imagination, as we will see in what follows.

For Peirce, mathematics is an observational science: it functions by means of a special mode of observation, i.e. that which is directed to the creations of our mind, to imaginary constructions with some degree of fixity (CP 2.305, 1901). Mathematicians construct figures, establish hypotheses and draw out their consequences and examine their relations, all by means of imaginary objects. In the imagination a type of diagrammatic representation is formed, that is constructed so that there would be something closely similar in every possible state of things to which the hypothetical description would be applicable, and is constructed so that it shall have no other characters which could influence the reasoning ( $\mathrm{CP}$ 4.233, c.1902). The diagram constructed in this way is modified in a process that takes place in the mind, since, as Fernando Zalamea has written, "the imagination of mathematical possibilities does not require marks" (Zalamea 2011: 94). Peirce describes this diagrammatic reasoning in the following way:

We form in the imagination some sort of diagrammatic, that is, iconic, representation of the facts, as skeletonized as possible. The impression of the present writer is that with ordinary persons this is always a visual image, or mixed visual and muscular; but this is an opinion not founded on any systematic examination. If visual, it will either be geometrical, that is, such that familiar spatial relations stand for the relations asserted in the premisses, or it will be algebraical, where the relations are expressed by objects which are imagined to be subject to certain rules, whether conventional or experiential. This diagram, which has been constructed to represent intuitively or semi-intuitively the same relations 
which are abstractly expressed in the premisses, is then observed, and a hypothesis suggests itself that there is a certain relation between some of its parts - or perhaps this hypothesis had already been suggested. In order to test this, various experiments are made upon the diagram, which is changed in various ways. This is a proceeding extremely similar to induction, from which, however, it differs widely, in that it does not deal with a course of experience, but with whether or not a certain state of things can be imagined. Now, since it is part of the hypothesis that only a very limited kind of condition can affect the result, the necessary experimentation can be very quickly completed; and it is seen that the conclusion is compelled to be true by the conditions of the construction of the diagram. This is called "diagrammatic, or schematic, reasoning. (CP 2.778, 1901)

The imagination thus plays a central role in this type of reasoning, which Peirce calls 'diagrammatic' or 'schematic,' and which has nothing to do with the course of experience, but rather with whether a certain state of things can be imagined or not. Daniel Campos has described the skills necessary for the mathematician: power of imagination to create hypothetical presentations, power of concentration to discriminate between mathematically essential and superfluous relations, and power of generalize on the basis of the characters and relations represented (Campos 2009: 137). Mathematics requires perfect imaginability as well as an extreme familiarity with spatial relations (CP 4.246, c.1902). On another occasion Peirce wrote that "mathematics calls for the profoundest invention, the most athletic imagination, and for a power of generalization" (CP 4.611, 1908).

Mathematics is purely deductive, and obtains necessary conclusions apodictically. This is necessary reasoning, i.e. applicable to all possible cases. Nevertheless, its manner of reasoning and its experiments are based on the imaginative study of an individual schema, or of various individual schemas which represent alternative possibilities. It might appear that when one constructs a figure in the imagination instead of on paper, any desired line might be added, but this is not the case. The image, as Peirce affirms, has a certain power of persisting such as it is and resisting metamorphosis. Thus, any fiction has certain characteristics which someone has attributed to it and which cannot be freely altered. Inner objects do offer a certain degree of resistance, though not in a fashion comparable to that of facts existing in reality (CP 5.45, 1903).

The necessary character of mathematics, thanks to the presence of the imagination, combines without contradiction with surprising discoveries, just as occur in any other observational science. The hypotheses of the mathematician are creatures of his own imagination, and at times surprising things are discovered. We thus learn that surprises are not linked only to the real world (CP 5.567, 1901) nor is the inventive power linked exclusively to abductions regarding that which exists. Experiments on diagrams, which question the nature of the relations involved, may provoke unintended and unexpected changes. All deductive reasoning involves an element of observation and discovery in the imagination.

31 It can thus be concluded with Peirce that the imagination is central to mathematical reasoning, necessary for invention and, in part, responsible of the superior certainty of the mathematician's results, because the mathematician's experiments, being conducted in the imagination upon objects of his own creation, cost next to nothing, and also because due to his reasoning only concerning hypothetical conditions the assurance of the mathematician is greater, not being open to unknown conditions which may alter the results (CP 5.8, c.1907). 


\section{Imagination and Phenomenology} foundations in the imagination. The capacity for imagination is necessary in order to separate and study that which appears before us. Peirce distinguishes three types of separation. First, there are ideas which are little allied amongst themselves, with the result that consciousness of one of these ideas does not imply consciousness of the other. Hence, we can imagine red without imagining blue, and vice versa. This type of separation is termed a dissociation. Secondly, prescision occurs when, even in cases where two conceptions cannot be separated in the imagination, we can suppose one without the other, that is we can imagine data from which we should be led to believe in a state of things where one was separated from the other. Thus, we can suppose uncolored space, though we cannot dissociate space from color. In other words, prescision consists in imagining ourselves in situations in which certain elements of fact cannot be ascertained. For example, Peirce states that prescind the geometrical figure from color consists in imagining it to be so illuminated that its hue cannot be made out (CP 2.428, 1893). This is a different and more complicated operation than merely attending to certain elements and forgetting the rest, and cannot be carried out without the imagination. Thirdly, even when one element cannot even be supposed without another, they may ofttimes be distinguished from one another. Thus we can neither imagine nor suppose a taller without a shorter, yet we can distinguish the taller from the shorter. Peirce terms this manner of separation 'distinction' (CP 1.353, c.1880).

Peirce's categories, deduced from the phenomena and present in them all, are closely related to the imagination. How could we separate them without imagination? Furthermore, the categories constitute precisely that which cannot be dissociated in the imagination, although they can be prescinded. One category cannot be dissociated in imagination from the others. Peirce explains this feature as follows:

Now, the categories cannot be dissociated in imagination from each other, nor from other ideas. The category of first can be prescinded from second and third, and second can be prescinded from third. But second cannot be prescinded from first, nor third from second. The categories may, I believe, be prescinded from any other one conception, but they cannot be prescinded from some one and indeed many elements. You cannot suppose a first unless that first be something definite and more or less definitely supposed. Finally, though it is easy to distinguish the three categories from one another, it is extremely difficult accurately and sharply to distinguish each from other conceptions so as to hold it in its purity and yet in its full meaning. (CP 1.353)

The imagination is necessary in order to separate concepts and comprehend the categories: in order to imagine red without blue, or sound without a melody, and to realize that we cannot conceive of melody without sound (CP 1.353). We must imagine the primary qualities, which we cannot know in any other way. We can imagine a universe that consists of a single quality that never changes (CP 1.322, 1903). We need the imagination in order to achieve, for instance, a general impression of pain - or of any other quality - by imagining at the same time distinct types of pain without attending to their parts, or imagining a color at the same time that all the rest of our consciousness is utterly wiped out; we need the imagination in order to capture the monadic aspect of phenomena ( $\mathrm{CP}$ 1.424, 1893). We must also be imaginative in order to comprehend the second category, i.e. binarity. It is necessary to imagine two objects which are not merely 
thought as two, but of which something is true such that neither could be removed without destroying the fact supposed true of the other (CP 2.84, c.1902). In order to comprehend the third, on the other hand, we must imagine laws which have no occurrences: this is something which we can only imagine (CP 1.304, c.1904).

\section{Imagination and Semiotics}

\section{bounded solely by the limits of its own powers (CP 5.440, 1905). One of these imaginary} flights led Peirce, for example, to think of existential graphs, which have an extraordinary plasticity: "the success of existential graphs, which provide a unique set of uniform axioms for the classical calculus of propositions, the classic calculus of first order relations and some modal calculi, have their basis in the plasticity of certain rules of transformation situated on a continuum" (Zalamea 2010: 5). The graphs are related to imaginary worlds. When we work with them we employ, or at least imagine that we employ, different things, e.g. a sheet of paper of different tints on its two sides (CP 4.573, 1906). The first convention for these graphs is that there is an assertion sheet which is considered as expressing an assertion made by an imaginary person called a 'graphist.'

On the other hand, it should not be forgotten that logic, for Peirce, is much more than a mere discipline. Rather, it is a long and difficult art which he understood as a way of entering into human thought (CP 5.359, 1877). Peirce dared to sketch out the path by which knowledge is produced. For him, it was clear that the explanation of the process of arriving at discoveries could not be merely psychological, given that all the psychology in 
the world would leave the logical problem just as it was (CP 5.172, 1903). This process of discovery is structured and susceptible to a logical explanation: "there is a purely logical doctrine of how discovery must take place, which, however great or little is its importance, it is my plain task and duty here to explore" (CP 2.107, c.1902). Creativity acquires a logical form via abduction, thus putting imagination in the center, not only of logic, but of all human knowledge.

\section{Imagination and Ethics}

For Peirce, ethics is not limited to telling people what they must or must not do (MS 675, 1911; EP 2: 459; CP 2.198, c.1902); indeed it goes beyond a mere dichotomy. Peirce an ethics has to do with admirable conduct. "The righteous man is the man who controls his passions, and makes them conform to such ends as he is prepared deliberately to adopt as ultimate" (CP 5.130, 1903). Ethics, from the Peircean pragmatist point of view, is seen as our guiding ourselves in accordance with our reason, which can grow and invent the modes by which it will grow, and which has the capacity to go beyond what is given, acting in an interconnected fashion with the imagination and the rest of human capacities. Ethics consists in our embodying ideals in our lives, bringing us closer to our ends. Indeed, the imagination fulfills a fundamental function with regards to those ideals which must orient our conduct: man imagines what the consequences of fully carrying out his ideals would be, and asks himself what the esthetic quality of those consequences would be (CP 1.591, 1903). On this basis, they make resolutions and determinations which will guide their actions.

\section{The Connection of Reason and Imagination}

Before concluding, I will explain this relation between imagination and reason a little more in depth. I have upheld this relation throughout this entire article, and I will show now that the most important nexus between imagination and reason are the habits.

Imagination is necessary so that reason can function; it aids reason on the road to truth and in its interconnection with life, as a guide of action. Indeed, as Peirce states on one occasion, thought is the development of a belief-habit which takes place in the imagination (CP 3.160, 1880). Intelligence does not consist in feeling a certain way, but in acting in a certain way, taking into account that many times these actions are internal and occur in the imagination (CP 6.286, 1893). For Peirce, the formation of habits is one of the most essential ingredients of moral and logical self-control, and all self-control that is a result of training takes place in the imagination (CP 5.533, c.1905).

The fact that the imagination contributes to forming habits, states Peirce on another occasion, is precisely that which separates it from mere fantasy: "Day-dreams are often spoken of as mere idleness; and so they would be, but for the remarkable fact that they go to form habits, by virtue of which when a similar real conjuncture arises we really behave in the manner we had dreamed of doing" (CP 6.286, 1893). How does the imagination carry out this formation of habits which will determine our actions and our reasoning? Merely imagining oneself reacting in a specific way can cause, after numerous repetitions, the class of reaction that is imagined. We imagine cases, place mental diagrams before our mind's eye, and multiply these cases, until a habit is formed (CP 2.170, c.1902). We may imagine the occurrence of the stimulus, and think out what the 
results of different actions will be. One of these will appear particularly satisfactory; and then that mode of reaction "receives a deliberate stamp of approval" (CP 5.538, c.1902). That stamp implies the act of recognition as one's own, being placed by a deed of the soul upon an imaginary anticipation of experience. In some way, one knows what to expect from then on, what will happen, and when a similar occasion arises one will see that the habit has already been established. Peirce gives the following example:

I well remember when I was a boy, and my brother Herbert was scarce more than a child, one day, as the whole family where at table, some spirit from a "blazer," or "chafing-dish," dropped on the muslin dress of one of the ladies and was kindled; and how instantaneously he jumped up, and did the right thing, and how skillfully each motion was adapted to the purpose. I asked him afterward about it, and he told me that since Mrs. Longfellow's death he had often run over in imagination all the details of what ought to be done in such an emergency. It was a striking example of a real habit produced by exercises in the imagination. (EP 2: 413, 1907)

There are imaginary lines of conduct that shall give a general shape to our actual future conduct, and is what Peirce terms a resolve (CP 5.538). Habits are acquired in this way, not by muscular effort but rather by the internal acts of the imagination. Behaviour, affirms Peirce, is always partially controlled by the deliberate exercise of imagination and reflexion (CP 7.381, c.1902). Hence, as Andacht has indicated, preparation is everything, since speculating on an imaginary action may have the effect of helping us to effectively carry out that action at some still undetermined time in the future (Andacht 1996: 1268).

The imagination thus serves as a preparatory meditation for action. It allows us to know what must be and not merely what is in the actual world (CP 2.227, c.1897), and aids us in acting in consequence. It allows us to make a unitary consideration of all that must be done and when it should be done. The imagination thus produces real effects, not only mere fantasies.

In addition to the habits there are other mechanisms, which we can briefly indicate, involved in this interconnection of imagination with reason. The imagination is necessary, in the first place, for the surprise and doubt that put reasoning into motion. When something surprises us it is because the mind is filled up with an imaginary object that we anticipate, and which in the end does not occur. Doubt, for its part, is a state of hesitancy concerning an imagined state of things. A man in doubt is usually trying to imagine how he shall act when he finds himself in the imagined situation. In his imagination, he does not know which path to follow amongst those which are presented to him (CP 5.510, c.1905).

Imagination is equally necessary in order to escape from doubt and advance towards belief. The critical common sensist, writes Peirce, for example, must set himself to the systematic business of endeavoring to bring all his very general first premisses to recognition, and of developing every suspicion of doubt of their truth, by the use of logical analysis, and by experimenting in imagination (CP 5.517, c.1905). Every answer to a question that has any meaning, states Peirce, is a decision as to how we would act under imagined circumstances (CP 5.373, 1877). To answer questions, man makes abstractive observations, makes in his imagination a sort of skeleton diagram, or outline sketch, and considers what modifications would require to be made. There are questions, and not only in mathematics, which can be resolved via imaginary experimentation, cases in which a generalization is needed, and when at last we arrive at a belief, that belief, which will determine our action, is active in the imagination. A belief is an intelligent habit upon which we shall act when occasion presents itself, and we virtually resolve to act as if 
certain imagined circumstances were perceived (CP 2.435, c.1893). The substance of beliefs can therefore be represented in the schemata of imagination, that is to say, in continuous series of images, these composites being accompanied by conditional resolutions as to conduct. (CP 5.517, c.1905).

Finally, the imagination is necessary in order to produce expectations. Peirce holds that an expectation is a kind of image in the imagination characterized by vague and fluid contours, a general idea which will govern the individual when it occurs. An expectation is a habit of imagining, an affection of consciousness which can be directly compared with that which occurs later (CP 2.148, c.1902).

\section{Conclusion}

Truth must first be imaginable and imagined. In order to advance in knowledge one must explore not only the limits of experience, but also those of the imagination, something which has not been sufficiently taken into account. It has always been said that knowledge for Peirce starts with experience, but it is frequently forgotten that this experience can and must also be imagined. Reason and imagination need one another. The order and rigor of reason and the flexibility and freedom of the imagination complement one another, contributing to more reasonable and aesthetic thoughts and acts.

A great part of our reasoning occurs through hypotheses, which cannot occur without imagination, or else through diagrams, which are applied to a better understanding of imaginary states of things, and help to analyze reasonings and to render ideas clear. We need the imagination for certain mental operations, in order to acquire habits, to separate, to doubt and to believe. Imaginary observation, holds Peirce, is the most essential part of reasoning (CP 4.355, c.1903). We need the imagination in order to explore consequences, clarify con- cepts and advance in knowledge.

It is therefore essential to develop the imagination, that tool which works together with reason, or better, which orients it and even houses it. Mere imagination is useless, but the imagination is not mere: without it there is nothing, intellectually speaking. The imagination works in harmony with the rules dictated by the reason in order to construct knowledge, to provide explanations, to express qualities, to envisage possible worlds, to generate habits and actions. "Imagination and reason go hand in hand, and it is only by means of their complete conjunction that man - slowly and sinuously, along paths full of ups and downs, advances and retreats, through literary, philosophical and scientific trends - partially unveils strange secrets which should have transcended him" (Zalamea 2009: 49). The cultivation of the imagination is not only essential for artistic and scientific creativity, but also for a greater attainment of reasonableness in general. In order that our reason be more productive, we must stimulate our imagination, since they are closely connected, to the point that thought "develops in the imagination." 


\section{BIBLIOGRAPHY}

ALEXANDer T. M., (1990), “Pragmatic Imagination," Transactions of the Charles S. Peirce Society, 26, $325-48$.

ANDACHT F., (1996), "El lugar de la imaginación en la semiótica de C. S. Peirce," Anuario Filosófico, $\mathrm{XIX} / 3,1265-89$.

Callaway H. G., (2007), “Abduction, Pragmatism, and the Scientific Imagination,” Apply- ing Peirce Conference, Helsinki. Electronic version in [philpapers.org/rec/CALAPA3].

CAMPos D., (2009) "Imagination, Concentration, and Generalization: Peirce on the Reason- ing Abilities of the Mathematician," Transactions of the Charles S. Peirce Society, 45 (2), 135-56.

EMERSON R. W., (1875), “Poetry and Imagination," in Letters and Social Aims, Boston, Osgood.

PEIRCE C. S., (1931-58), Collected Papers (CP), vols. 1-8, Hartshorne, C., Weiss, P. and Burks, A. W. eds., Cambridge, MA, Harvard University Press. Electronic Edition of J. Deely, Charlottesville, VA, InteLex.

PEIRCE C. S., (1992-98), The Essential Peirce. Selected Philosophical Writings (EP), vols. 1-2, Peirce Edition Project eds., Bloomington, Indiana University Press.

PEIRCE C. S., (1982- ), Writings of Charles S. Peirce: A Chronological Edition (W), vols. 1-6, Fisch, M. H. et al. eds., Bloomington, Indiana University Press.

PEIRCE C. S., (1978), microfilms of his manuscripts (MS), Houghton Library, Cambridge, MA, Harvard University Library, Photographic Service.

RESTREPO M., (2011), “Representación interpretante, enlace hermenéutico," IV Jornadas Internacionales Peirceanas, México D. F., 3-6 May. Electronic version in [unav.es/gep/ ArticulosOnLineEspanol.html].

ZALAMEA F., (2011), “Creatividad y plasticidad en el Logic Notebook,” Cuadernos de Sistemática Peirceana, 3, 79-102.

ZALAMEA F., (2010), “Creatividad y plasticidad en los gráficos existenciales," Cuadernos de Sistemática Peirceana, 2 , 5-24.

ZALAMEA F., (2009), “Faneroscopia, filosofía natural y literatura. 'La esfinge' en Peirce, Emerson, Poe y Melville," Cuadernos de Sistemática Peirceana, 1, 33-52.

\section{ABSTRACTS}

Charles S. Peirce held a view of human reason as creative. The objective of this article is to explore more deeply the Peircean conception of imagination, indispensable for the correct functioning of reason. The connection of reason and imagination is necessary in order to be able to interpret the world, to advance towards the truth and to direct our own actions. In this paper I will explain the principal forms in which these faculties interact, and will provide examples taken from the Peircean corpus. 


\section{AUTHOR}

SARA BARRENA

Grupo de Estudios Peirceanos, University of Navarre, Spain sbarrena[at]unav.es 